\title{
LA IMPORTANCIA DEL PROTOCOLO EN LAS RELACIONES PÚBLICAS INSTITUCIONALES
}

\author{
Martínez Sánchez, Mํㅡㄹ Carmen ${ }^{1}$ \\ Junta de Andalucía \\ mariac.martinez.sanchez@juntadeandalucia.es
}

Material original autorizado para su primera publicación en la revista académica REDMARKA. Revista Digital de Marketing Aplicado.

https://doi.org/10.17979/redma.2013.01.011.4806

Recibido: 15 Octubre 2013

Aceptado: 3 Diciembre 2013

\section{Resumen}

Las instituciones y organizaciones públicas o privadas tienen cada vez más oportunidades de estrechar lazos con la sociedad a través de múltiples acontecimientos y actividades (congresos, jornadas, convenios, patrocinios, entregas de premios). A nuestro juicio, la comunicación protocolaria ha de ser asumida como parte de una estrategia integral de la organización para lograr proyectar la presencia e imagen pública del poder.

El protocolo, definido como conjunto de normas y disposiciones legales vigentes que,

\footnotetext{
${ }^{1}$ Funcionaria de la Junta de Andalucía desde 1984, ha desempeñado durante los últimos veinte años diferentes puestos de trabajos como asesora parlamentaria, jefa de prensa, y colaboradora en la organización de eventos para los gabinetes de diversos miembros del Consejo de Gobierno andaluz.

Doctora por la Universidad de Sevilla y Licenciada en Ciencias de la Información por la Complutense, se ha especializado en los ámbitos de Relaciones Públicas y Protocolo, Comunicación Institucional y Marketing Político, así como Protocolo Deportivo.

En 2010 obtuvo el Premio Blas Infante de Estudio e Investigación sobre Administración y Gestión Pública, en su modalidad A, XIII Edición, otorgado por el Instituto Andaluz de Administración Pública de la Junta de Andalucia, por su trabajo "El protocolo como herramienta estratégica de comunicación. Una constante histórica y estudio de casos actuales".

Ha dirigido y participado en diferentes cursos y jornadas sobre comunicación protocolaria organizados por el Instituto Andaluz del Deporte de la Junta de Andalucía y colabora como Ponente Invitada en el Seminario de Protocolo del Máster en Comunicación Institucional y Política que organiza el Departamento de Periodismo II de la Facultad de Comunicación de la Universidad de Sevilla, dirigido por el Dr. Juan Luis Manfredi Mayoral.
} 
junto a los usos, costumbres y tradiciones de los pueblos, rige la celebración de los actos oficiales, es una constante histórica que ha sido utilizada para visualizar y representar los diferentes estatus sociales.

Estrategias, técnicas y tácticas protocolarias pueden llevar al éxito o hundir en el fracaso la consecución de los objetivos de una organización. $Y$ los gobiernos son conscientes de ello porque política y comunicación no pueden vivir por separados. En este ámbito, defendemos que la comunicación protocolaria, presente siempre en el proceso de planificación, organización y gestión de los actos públicos oficiales, constituye un elemento fundamental al servicio de las relaciones públicas institucionales.

Palabras clave: protocolo, imagen, poder.

\begin{abstract}
Public or private institutions and organizations have increasing opportunities to strengthen ties with the company through multiple events and activities (congresses, conferences, conventions, sponsorships, awards). In our opinion, the protocol communication must be taken as part of a comprehensive strategy for the organization to project their presence and public image of power.
\end{abstract}

The protocol, defined as a set of rules and legal provisions which, together with the practices, customs and traditions of the people, governing the holding of official acts, is a historical constant that has been used to visualize and represent different social status.

Strategies, tactics and formal techniques can lead to success or failure in achieving the objectives of an organization. Governments are aware because policy and communications cannot exist separately. On this point, we argue that the protocol communication, which is always present in the process of planning, organization and management of official public events, is a key element in the service of institutional public relations.

Keywords: protocol, image, power. 


\section{Resumem}

As instituições e organizações públicas ou privadas têm cada vez mais oportunidades de estreitar laços com a sociedade através de múltiplos acontecimentos e actividades (congressos, jornadas, convênios, patrocínios, entregas de prêmios). A nosso julgamento, a comunicação protocolaria tem de ser assumida como parte de uma estratégia integra.

O protocolo, definido como conjunto de normas e disposições legais vigentes que, junto aos usos, costumes e tradições dos povos, rege a celebração dos actos oficiais, é uma constante histórica que tem sido utilizada para visualizar e representar os diferentes status sociais.

Estratégias, técnicas e tácticas protocolarias podem levar ao sucesso ou afundar no falhanço a consecução dos objectivos de uma organização. E os governos são conscientes disso porque política e comunicação não podem viver por separados. Neste âmbito, defendemos que a comunicação protocolaria, presente sempre no processo de planejamento, organização e gestão dos actos públicos oficiais, constitui um elemento fundamental ao serviço das relações públicas institucionais.

Palavras-chave: protocolo, imagem, poder.

\section{INTRODUCCIÓN}

El protocolo en España ha experimentado una importante evolución y actualización no sólo por la modernidad que destaca en la organización de actos sino también, por ejemplo, en la ordenación del Estado, donde prima el carácter institucional frente al personal, la elección por sufragio universal frente a la designación y la presencia de las instituciones de todo el país, frente al centralismo de la capital del Reino.

El protocolo permite la representación visual y plástica del poder y, a nuestro juicio, debe formar parte de las estrategias y tácticas que las Instituciones apliquen a través de su proyecto global de comunicación institucional. La acepción mayormente aceptada para la palabra protocolo es la de un conjunto de normas y disposiciones legales vigentes que, 
junto a los usos, costumbres y tradiciones de los pueblos, rige la celebración de los actos oficiales. Estamos hablando de reglas pero también de técnicas.

El protocolo no es una invención moderna, ni tampoco un conjunto de normas que obligan a un comportamiento humano rígido, encorsetado, poco espontáneo, extravagante, cortés y superficial. Entendemos que el protocolo actual abarca mucho más que una ordenación espacio-temporal de una ceremonia oficial para colocar a las personas y entidades con arreglo a sus méritos y representación. El protocolo da muestras de orden, equilibrio y actualidad en la organización de los actos. Es sinónimo de cortesía y respeto entre ciudadanos pero también de profesionalidad, mérito y creatividad de los responsables técnicos. Y, por supuesto, describe un código de comportamiento en las relaciones sociales en la vida pública.

En un sentido más amplio, Fernando Ramos i entiende que el protocolo se configura como una «serie de ritos, de costumbres, de ceremonias que forman parte de la vida de los ciudadanos comunes, desde la cuna a la tumba». Nos recuerda también este autor la definición dada por Sabino Fernández Campo, ex Jefe de la Casa de Su Majestad el Rey, Juan Carlos I: «El protocolo es un componente del mundo civilizado que sirve para graduar y matizar adecuadamente las relaciones de los individuos y dígase lo que se diga, tiene una trascendencia importante para la susceptibilidad de las personas y el buen orden de las cosas». 
Cuando nos remontamos a los orígenes del protocolo, nos sorprendernos por la importancia que esta disciplina ha tenido en el devenir histórico. Innumerables acontecimientos han sido marcados por las reglas o las costumbres de la época. Desde el banquete romano, por citar un ejemplo, hasta la exaltación de los símbolos «patrios», pasando por la vestimenta, la forma de relacionarse en sociedad o la presentación del poder ante el pueblo. Todos son elementos que encuadramos dentro de las reglas del protocolo que han definido distintas etapas históricas de la humanidad.

Hoy, muchos pueden pensar que las reglas de protocolo son códigos de comportamiento social pasados de moda, clasistas, pero lo cierto es que esas deferencias, esa cortesía, ese saber estar y saber tratar a los demás, el respeto en definitiva, engrandece a quien lo aplica.

Para nosotros, como decía el Embajador Tomás Chávarriiii, diplomático español y ex jefe de Protocolo del Estado, «el protocolo no implica ni servidumbres ni servilismos. No supone ni vencedores ni vencidos. El protocolo se sigue aplicando incluso cuando dos naciones están enfrentadas o en guerra».

Por citar un acontecimiento internacional a este respecto debemos destacar el Congreso de Viena, donde se establecieron los principios esenciales de un único protocolo social y diplomático y de las Relaciones Internacionales en Europa hasta nuestros días. Esta Conferencia Internacional fue convocada, según los acuerdos adoptados mediante el Tratado de París de 30 de mayo de 1814, con el objeto de restablecer las fronteras territoriales de Europa una vez concluidas las Guerras Napoleónicas con la abdicación de Napoleón I Bonaparte.

La reunión se celebró desde el 1 de noviembre de 1814 hasta el 8 de junio de 1815 en Viena, capital del Imperio Austríaco, y los pactos alcanzados tuvieron una vigencia casi inamovible en los territorios orientales y centrales europeos hasta el final de la I Guerra Mundial en 1918. Participaron las principales potencias, que estuvieron representadas por sus respectivos embajadores: Austria (Metternich), Gran Bretaña (Castlereagh), Rusia (Alejandro I), Prusia (Humbolt) y Francia (Talleyrand). España intervino como potencia de 
segundo orden, junto a Suecia y Portugal.

Citaremos una situación que se produjo en la firma del Acta final de esta Convención, que relata el ex Embajador de la República italiana en España, Leonardo Visconti di Modrone ${ }^{\text {iv }}$, y que nos demuestra la importancia del detalle en la celebración de los actos públicos. Como la Sala donde se iba a producir la firma tenía cuatro puertas, y eran cinco los embajadores que debían rubricar el Acuerdo, los organizadores tuvieron que abrir una nueva puerta para que todos ellos accedieran a la vez y se visualizara la igualdad de tratamiento a los diferentes Estados.

El Congreso de Viena no solo fue la primera Conferencia de Paz moderna, sino que los procedimientos utilizados en él sirvieron de pauta para las conferencias internacionales siguientes e incluso para las que se celebran en la actualidad.

A lo largo de la historia, todas las culturas y civilizaciones han establecido sus propias normas y costumbres, sus ceremonias para representar al poder en su máximo esplendor y persuadir a sus públicos sobre la grandeza y bonanza del mismo, la importancia de sus decisiones o la necesidad de mantener a los gobernantes. En definitiva, el objetivo ha sido proyectar la mejor imagen posible de la organización y conseguir la confianza de los receptores de los mensajes emitidos, ya sean reales o simbólicos, verbales o no verbales, explícitos o implícitos.

Las organizaciones públicas o privadas consolidan una imagen positiva interna y externa, entre otros medios, a través de la organización de sus actos, gracias a la utilización de ciertos códigos de conductas, así como de las formas adecuadas de relacionarse. Este es uno de los beneficios intangibles que se obtiene mediante las relaciones institucionales.

A través de una comunicación no verbal, interpersonal y colectiva no masiva, que denominamos comunicación selectiva, los actos públicos permiten a las organizaciones lanzar mensajes adecuados a sus objetivos y mostrar la imagen del poder y la filosofía en que se fundamentan sus ceremonias. 
En este sentido, la Doctora María Teresa Oterov apunta que "la imagen no se transmite, sino que se obtiene tras la percepción de una realidad". Y como bien apunta Marín Calahorrovi, "la Institución, en la mayoría de los casos, sólo existe ante la sociedad como imagen virtual, es decir, como realidad conformada a través de su presencia en los medios de comunicación". 
El protocolo, por tanto, configura una adecuada proyección no verbal de la organización y de sus relaciones con su entorno. Esas formas de relación deben demostrar eficacia en su planificación y desarrollo, y han de estar asumidas dentro de un proyecto de comunicación global de la entidad, para que genere confianza gracias a la perfección y al rigor que se transmite con la ejecución de los actos.

En todo este proceso comunicativo el protocolo se convierte, por tanto, en un aliado de primer orden a la hora de presentar a todos los públicos objetivos una identidad de la organización coherente con sus principios y valores, para que aquéllos perciban y se formen la imagen corporativa más acorde con dicha identidad.

\section{CUESTIÓN DE PROTOCOLO}

Los Servicios de Prensa del Palacio de la Moncloa emitieron un comunicado el 16 de mayo de 2012 en el que se informaba del telegrama de pésame enviado por el Presidente del Gobierno de España, Mariano Rajoy, tras el fallecimiento del escritor mexicano Carlos Fuentes. Hasta aquí, todo correcto. Un acto protocolario adecuado dada la trascendencia del hecho, había fallecido uno de los más ilustres escritores de la literatura latinoamericana.

Sin embargo, la nota de prensa causó un enorme revuelo porque en el encabezamiento se recogía que Carlos Fuentes era el padre de Artur Mas, presidente de la Generalitat de Cataluña: "Pésame del Presidente del Gobierno por el fallecimiento del escritor Carlos Fuentes padre de Artur Mas"vii.

El problema se había producido porque los responsables del área de Comunicación de la Moncloa reutilizaron una plantilla, con la que habitualmente elaboran los comunicados sensibles, empleada para el pésame que Rajoy envió a Mas tras el fallecimiento de su padre hacía dos meses. El copia y pega les jugó una mala pasada tras la que, una vez advertida, el texto fue corregido de inmediato.

Este ejemplo es solamente un desafortunado incidente técnico pero si tomamos como 
objeto de estudio las relaciones entre ambos ejecutivos podemos afirmar que los desencuentros de carácter protocolario entre el Gobierno de España y la Generalitat de Cataluña, o viceversa, han sido frecuentes a lo largo de la historia debido a las tensiones políticas que se generan por la causa soberanista catalana.

Es el trasfondo que subyace, por ejemplo, en la situación producida con motivo de la asistencia de la vicepresidenta del Gobierno español Soraya Sáenz de Santamaría al acto de entrega de las Medallas de Honor de Fomento del Trabajo y de los Premios Carles Ferrer Salat, organizado por la patronal catalana el pasado mes de octubre. Desde el Palacio de la Moncloa se informó que la vicepresidenta asistía como titular en funciones del ejecutivo debido a la ausencia de Rajoy, que se encontraba en la Cumbre Iberoamericana celebrada recientemente en la ciudad de Panamá. El presidente de la Generalitat, Artur Mas, decidió entonces no asistir al evento, aunque estaba previsto que lo hiciera, al conocer que la vicepresidenta ostentaría la representación del gobierno y que, por lo tanto, él no iba a presidir la ceremonia.

Según fuentes del gobierno catalán, el presidente de la Generalitat, "sólo participa en actos oficiales que presida o cierre él, salvo en el caso de presencia del Rey, del Príncipe o del presidente del Gobierno". Artur Mas optó por delegar la representación del gobierno catalán en el consejero de Empresa y Empleo, Felip Puig. Su silla se dejó sin ocupar por los organizadores, lo que hizo más evidente aún la ausenciaviii. 


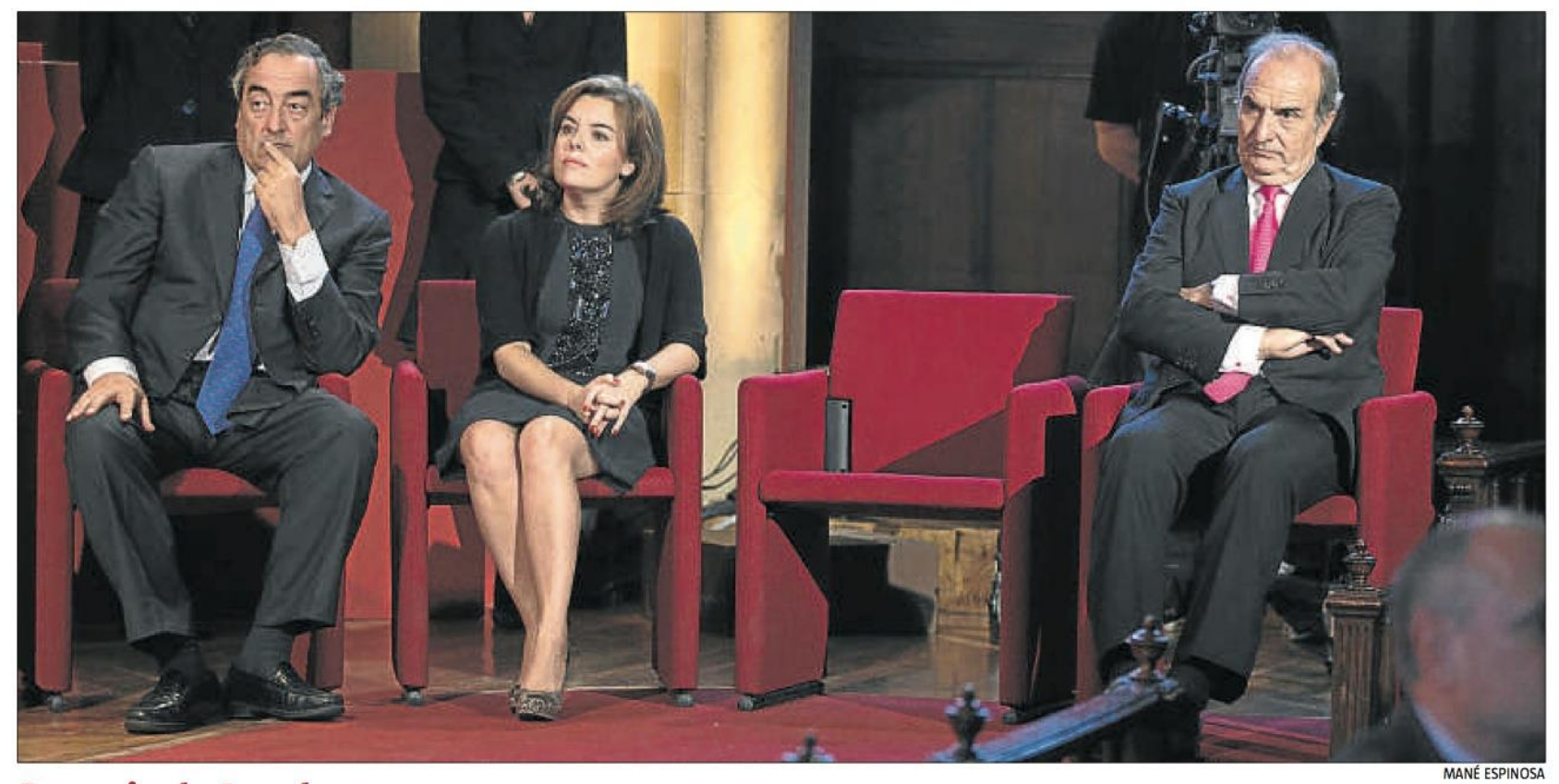

Ausencia destacada. El asiento de Mas junto a Sáenz de Santamaría fue ocupado por el conseller de Empresa, Felip Puig. A la izquierda, Juan Rosell, presidente de la CEOE, y a la derecha, el de Foment, Joaquim Gay de Montellà. PoLíticA 12

La cuestión política excede en este caso a la diferencia de interpretación protocolaria, que queda aclarada en el Real Decreto de Precedencias vigente en el Estado español, cuyo artículo 9 establece que "La persona que represente en su cargo a una autoridad superior a la de su propio rango no gozará de la precedencia reconocida a la autoridad que representa y ocupará el lugar que le corresponda por su propio rango, salvo que ostente expresamente la representación de Su Majestad el Rey o del Presidente del Gobierno ".

A los pocos días de producirse este incidente, calificado por los medios de comunicación como "desacuerdo de protocolo" o "plantón", Barcelona acogía el I Foro Económico del Mediterráneo, que reunió a los ministros de Exteriores de diez países de la UE y del norte de África. Nuevamente volvió a generarse cierta polémica porque el presidente Rajoy inauguró el Foro pero desde Moncloa no se accedió a modificar el programa para que el presidente de la Generalitat, Artur Mas, dirigiese unas palabras de bienvenida a los asistentes al inicio del acto.

El presidente catalán recibió a los participantes en el Palacio de Pedralbes, saludó al presidente del Gobierno y, a continuación, se marchó a la sesión plenaria prevista en el Parlamento sin esperar a escuchar la intervención de Rajoy. En esta ocasión ix, el 
presidente catalán defendió que "no hay problemas protocolarios, hay imposiciones protocolarias que generan problemas".

Y es aquí donde afirmamos que el protocolo debe ser entendido como un instrumento que facilita la representación visual del poder y cuya finalidad es conseguir una percepción positiva por parte de los públicos. Se equivocan pues quienes lo utilizan con otros objetivos políticos y las consecuencias pueden ser como las del retorno de un boomerang, que el cazador es cazado.

Estamos ante una herramienta estratégica de comunicación utilizada a través de los tiempos para proyectar la mejor imagen de las personas e instituciones que constituyen el poder establecido en forma de Estado. La normativa oficial que lo regula en España, el Real Decreto 2099/1983, de 4 de agosto, por el que se aprueba el Ordenamiento General de Precedencias en el Estado, que establece los principios de organización de todo acto oficial y unas prelaciones en función de un rango, colegiado o individual, no puede ser utilizada como arma para imponer, ofender o defenderse según las circunstancias o coyuntura política.

Hay quien ironiza sobre la importancia del protocolo para la vida de los ciudadanos, como ha ocurrido con el artículo El protocolo de una crisis, publicado por el periodista Jordi Évole $^{\mathrm{x}}$ a raíz de los episodios narrados con anterioridad. Es evidente que esta polémica no nos "quita el sueño" a los españoles, que lo que nos preocupa son los recortes, el paro, la exclusión, la pobreza o la involución de los derechos sociales y laborales que estamos sufriendo en nuestro país en los últimos años. Pero tampoco hay que menospreciar esta herramienta a la hora de mantener unas adecuadas relaciones institucionales.

Por su parte, otros autores destacados, como el asesor de comunicación y consultor político Antoni Gutiérrez-Rubíxi, difieren y opinan sobre la importancia simbólica del protocolo como instrumento en la construcción del poder y su legitimidad. $\mathrm{Y}$, en este sentido, entendemos que unas palabras, un gesto, un fallo de organización, un descuido, una decisión inapropiada pueden provocar, por ejemplo, un conflicto diplomático. Y que el protocolo debe favorecer siempre la consecución de un acuerdo o la solución del conflicto, 
nunca formar parte del problema.

\section{CONCLUSIONES}

La utilización del protocolo como herramienta estratégica de comunicación ha sido, es y será una constante histórica. El protocolo es una ciencia milenaria. El poder establecido ha utilizado a lo largo de la historia numerosas estrategias, técnicas y tácticas para visualizar y representar los diferentes estatus sociales.

Pero el protocolo es parte de la comunicación institucional, que a su vez es una obligación legal, ética y política que los representantes públicos tienen con la ciudadanía. Este tipo de comunicación, además de informar y formar, tiene también como objetivos proyectar una imagen positiva, ganar la confianza de los públicos y conseguir incrementar la notoriedad de los representantes políticos.

Y, en este sentido, el protocolo juega un papel fundamental porque, a través de la organización de un acto público oficial, podemos crear el marco adecuado para realizar una transmisión de mensajes acordes con los objetivos de la institución. Por tanto, forma parte de las estrategias y tácticas que las organizaciones aplican con su proyecto de comunicación institucional y persigue además los siguientes objetivos:

- Generar confianza a través del orden, de la eficacia, de la discreción y de la perfección que se transmite, de forma no verbal, en la ejecución de los actos públicos.

- Ofrecer una imagen de marca que nos diferencie positivamente frente a otras Instituciones.

- Mostrar los valores, los principios y el modelo organizativo de la Institución.

- $\quad$ Prestar un servicio de calidad, en el que cada acto público debe estar presidido por el respeto a lo que representa la Institución, la seriedad, la sencillez, la elegancia, la solemnidad y el rigor.

- $\quad$ Y afianzar la credibilidad y la notoriedad de los cargos públicos y de la propia Institución. 
En definitiva, la comunicación protocolaria representa una parte esencial para mostrar la excelencia de la organización y para proyectar la imagen de las personas e instituciones que constituyen el poder establecido en forma de Estado. Del éxito o fracaso de un acto dependerá que ofrezcamos una imagen positiva o negativa de nuestra organización, que consigamos emitir correctamente el mensaje implícito o explícito, y que cumplamos el objetivo que justifica al propio acto. La meta de los responsables de protocolo es configurar una adecuada proyección no verbal de la identidad de nuestra organización y de sus relaciones con su universo.

\section{BIBLIOGRAFÍA}

\section{Publicaciones no periódicas}

CHÁVARRI DEL RIVERO, Tomás, Protocolo Internacional. Tratado diplomático, Ediciones Protocolo, Colección Ceremoniales, Madrid, 2004.

MARÍN CALAHORRO, Francisco, Protocolo y Comunicación. Los Medios en los Actos Públicos, Editorial Bayer Hnos. S.A., Barcelona, 2000.

MARTÍNEZ SÁNCHEZ, María del Carmen, El Protocolo como herramienta estratégica de comunicación. Una constante histórica y estudio de casos actuales, Instituto Andaluz de Administración Pública, Junta de Andalucía, Sevilla, 2010.

OTERO ALVARADO, María Teresa, Teoría y Estructura del Ceremonial y el Protocolo, MERGABLUM, Edición y Comunicación, S.L., Sevilla, 2000.

RAMOS FERNÁNDEZ, Fernando, La comunicación corporativa e institucional. De la imagen al protocolo, Editorial Universitas, S.A., Madrid, 2002.

VISCONTI DI MODRONE, Leonardo, Conferencia sobre El Protocolo Diplomático impartida el 22 de noviembre de 2007 durante la celebración del VIII Congreso Internacional de Protocolo, Roma (Italia).

\section{Internet}

http://estaticos.elperiodico.com/resources/pdf/7/9/1337184394497.pdf

http://santiagonzalez.files.wordpress.com/2013/10/portada-lv.jpg 
http://www.rtve.es/noticias/20131023/rajoy-acude-hoy-foro-del-mediterraneo-marcado-polemica-sobrepresencia-artur-mas/773520.shtml

http://www.elperiodico.com/es/noticias/al-contrataque/protocolo-crisis-por-jordievole-2786970

http://blogs.elpais.com/micropolitica/2013/10/rajoy-mas-y-el-protocolo.html

'RAMOS FERNÁNDEZ, Fernando, La comunicación corporativa e institucional. De la imagen al protocolo, Editorial Universitas, S.A., Madrid, 2002, p. 111.

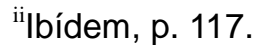

iii CHÁVARRI DEL RIVERO, Tomás, Protocolo Internacional. Tratado diplomático, Ediciones Protocolo, Colección Ceremoniales, Madrid, 2004, p. 38.

${ }^{\text {iv }}$ VISCONTI DI MODRONE, Leonardo, Conferencia sobre El Protocolo Diplomático impartida el 22 de noviembre de 2007 durante la celebración del VIII Congreso Internacional de Protocolo, Roma (Italia).

vOTERO ALVARADO, María Teresa, Teoría y Estructura del Ceremonial y el Protocolo, MERGABLUM, Edición y Comunicación, S.L., Sevilla, 2000, p. 304.

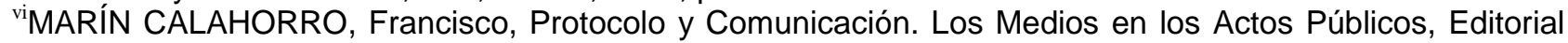
Bayer Hnos. S.A., Barcelona, 2000, pp. 48 y 49.

vii http://estaticos.elperiodico.com/resources/pdf/7/9/1337184394497.pdf

viii http://santiagonzalez.files.wordpress.com/2013/10/portada-Iv.jpg

ix http://www.rtve.es/noticias/20131023/rajoy-acude-hoy-foro-del-mediterraneo-marcado-polemica-sobrepresencia-artur-mas/773520.shtml

${ }^{x}$ http://www.elperiodico.com/es/noticias/al-contrataque/protocolo-crisis-por-jordievole-2786970

${ }^{x i}$ http://blogs.elpais.com/micropolitica/2013/10/rajoy-mas-y-el-protocolo.html 